\title{
REVOLUTION IN THE COGNITIVE PSYCHOLOGY OF DEVELOPMENT
}

\author{
Elena A. Sergienko \\ Institute of Psychology, Russian Academy of Sciences \\ Moscow
}

The recent revolutionary changes in the cognitive psychology of development, touching upon the basic conceptions of psychology, are generalized in this article. The problem of theoretical changes connected with systemic evolutionary approach, dynamic nonlinear system theory, and connectionism, is discussed. The author analyses four basic theses of revolutionary changes: from sensory-motor infant to representative one; from the leading role of activity to the unity of perception and action; about the continuity of the subject formation, instead of axiom of subjectivity of the adult, mature person; about the continuance of genetic and environmental instead of social primacy in the mental development of a person. There are key arguments of new conceptions, obtained by the author and other researchers.

Keywords: revolutionary changes, cognitive development, early ontogenesis, representative infant, perception and action, ontogenesis of subjectivity, theory of mind, theories of mental formation.

Revolution in infancy psychology has begun in the 60th and gradually included practically all representations of mind origins in the human ontogenesis. First of all, it has touched upon the issue of knowledge origin, role of actions in the mental development, mental representations' formation, basics of the person, and subjects. It is impossible to consider all the fundamental questions, affected by empirical-theoretical revolution; so, the author dwells on several basic and fundamental moments, which were analyzed by her pupils, colleagues, and herself over the time of more than 30 years of work.

The basic changes in the developmental psychology, touching upon the basic problems of psychology are related to the research of early human ontogenesis. The ontogenesis research shows that development of the most organized levels depends on base, primary steps. These base, primary periods of human development have not been adequately ex- 
plored, especially in our domestic psychology. In the world psychological science, the basic stress of mental processes research was set on the area of infant's development. It is manifested by increasing number of publications, and by discussion of the problems of early stages of development in traditionally "adult" and authoritative journals, such as "Cognition" and "Trend of Cognitive Sciences". Some new journals have gained popularity among scientists: "Developmental Science", "Infancy" etc.

It is explained by two reasons. First, the theoretical discussions on one of the basic problems of psychology - determination of mind has become pointed, by going on to the new level of generalization of empirical material and new theoretical approaches. The practical strategies of organization of education, training, correction, and comprehension of the rehabilitation opportunities of one or another mental disorder depend on the answer to the question - how the biological (genetic) and environmental development factors interact. Second, methods of infancy study are improved, allowing to get more reliable and reproducible results. Increase of theoretical and experimental interest to the period of early ontogenesis has led to the planned reconsideration of the representations of human mental development, especially his cognitive abilities. The very fundamental and detailed development of psychology problems, from the position of the system - the evolutionary dynamics, is the most topical and perspective in the context of the world psychological science. This thesis is confirmed by the system-dynamic approach (Dynamic systems' approach) - authors Esther Thelen and Linda Smith (Thelen, and Smith, 1994; 1998), which is the most widespread, not only in developmental psychology, but in the general psychology as well. Many theses of the given approach are deeply intertwined with the theses of the system-evolutionary approach.

The authors, specifying the basic origins of the approach, name the nonlinear physics and N.N. Bernstein's works. Many principles of the dynamic system approach are consistent with the representation of the system-evolutionary approach, which is intensively developed in the domestic science (Aleksandrov, 2004; Field, Woodson, Greenberg, and Cohen, 1982; Gregory, 1970; Lomov, 1984; Naisser, 1981). These approaches represent the unity of genetic and environmental in human mind, develop theses on the level system nature of development and mind functioning. However, there are some essential distinctions between them.
1. Self-organization - the main principle of development and behaviour. The continuity of systems change includes the continuity of environmental requirements changes that leads to the adaptive behaviour. (The given thesis is elaborated in the system-evolutionary theory as it explains environmental attack selectivity).

2. An external behaviour of the individual is caused by neuronal systems. Movement from one condition of the organism to another - is a continuously connected ensemble of related components. The coalition nature of the systems components is of fundamental importance: no component is preferred, that provides the occurrence of new forms, owing to the shifts in the coalition interaction of the systems components and new components inclusion. One can compare this thesis to the thesis of the system approach on non-reducibility of the system to any of its components.

3. Development is a continuous change of forms of behaviour intime; stable conditions change, lose stability and change in time.

4. Development is learning. There is no sense in dividing these pro cesses. The organism continuously and actively changes, and its neuronal conditions and physical parameters change as well. Some changes hap pen quickly, the others take many months and years. Processes of learning and development are interlaced with one another. Every new condition depends on the previous one (This thesis most closely corresponds to the system-evolutionary approach).

5. There is no sense in dividing "knowledge" and "actions". There is no sense to ask the child what he really "knows" and what he can "do".

In the child's behaviour all these moments are unified for the task performance. The behaviour can be stable at the performance of many tasks and fragile at the performance of the same tasks, but under different circumstances. Therefore, there is no gap between perception and action, knowledge and behaviour.

The theory of nonlinear dynamic systems is applied mainly to the motor development and functioning. While applying this theory to the cognitive development, the authors experience some difficulties. Theory of Thelen and Smith characterizes knowledge as dynamic, adaptive, and self-organizing. It occurs little by little, as motor, from one system condition into another. Infants improve cognitive skills through the processes of environment study, based on perception and action. Infants' actions are made as self-organizing motor and neuronal subsystems that lead to 
the stable conditions of coordination at meeting a problem. Hence, action, inseparably from perception and complex "perception - action", is a basis of natural categories in accordance with which all cognitive skills are formed in future. Transition from perception to knowledge inevitably assumes formation of categories. According to the theory of Thelen and Smith, formation of categories is self-organization of perception and action connected with it. However, the theory experiences complexities when interpreting data on very early processes of categorization of infants and neonates (imitation of facial expressions and gestures is possible by neonates, selectivity is typical as early as the stage of prenatal development) (Meltzoff, and Moore, 1977; 1998; Reznick, Corley, and Robinson,

1997). It seems to be necessary to expect from the very beginning a cognitive readiness for selectivity, which underlies the categorization.

In spite of existing distinctions between the theory of nonlinear dynamic systems and connectionism, there is more similarity, than distinction (Thelen, and Bates, 2003). The self-organization principle is realized in the theory of connectionism, in the nonlinear dynamic system, and the system-evolutionary theory. Distinctions between the theory of nonlinear dynamic systems and connectionism lay to a greater extent in the following positions. The structuring role of the external information is recognized by all theories, but not equally. For the theory of nonlinear dynamic systems and for connectionism the role of the external information is critical. It can lead to absolutely various results, but results are not contained in the environment. Connectionism lays the great emphasis on the mutual relations of the external information and the internal structures. Internal, mental representations define the selectivity of the external information. "Hidden regulations" define the external consequences. While in Thelen-Smith theory, the external information actually plays the generating role.

Development of knowledge from simple to complex is the sensorymotor basis of cognition. This principle was the fundamental one in the theory of J. Piaget and in the theory of dynamic systems. Connectionism, to a greater extent, is centred on mental representations, defining the cognitive development. This distinction applies to "mental representations", which are absent in the theory of dynamic systems and considered by connectionism as the internal structures of development.

There are distinctions in the dynamic systems understanding in two modern approaches. The idea of nonlinear dynamic of changes, sensitivity to entry conditions, and unexpected transformations according to the type of catastrophe are common to these approaches. The transformations explain U-shaped development of functions, which takes place after gradual changes in certain amount of parameters. But systems change in the dynamic approach implies a coalition of perception and action, whereas connectionism is the dynamics of changes in the mental structures.

Some distinctions can be observed in the application of mathematical formalization in both approaches. Both theories widely use the mathematical device for descriptions' formalization. However, in the dynamic systems theories, formalization is directed to behaviour description (for example, dynamics of changes from pace to running), while in connectionism, the architecture and learning functions are formalized at the level of mental representations.

The author of the given work adheres to the opinion of the systemevolutionary approach, which is a kind of synthesis of three named directions. Sharing opinion of the principle of developments continuity, inseparability of genetic and environmental factors as full participators of development, I also agree with the representation about indirect developments by mental structures, i.e. recognizing the unity of perception and action, and considering the presence of at least crude generalized internal representations as a necessary part of this mechanism activity. I like the idea of dynamic systems and their changes by a principle of catastrophe, the gradual transformation of internal state. However, the dynamic approach does not give answers to many specific questions on the mechanisms of sensitivity and selectivity. Moreover, in the systemevolutionary approach, the principle of anticipatory development is emphasized as the basic one and the author has bent every effort to this principle development (Sergienko, 1992).

I would like to specify one more circumstance that explains the increasing popularity of the research on the early periods of mental development. At the present stage of psychology development, the integration of different areas of psychological knowledge has been outlined. Interosculation of different paradigms of research, comprehension of the common subject in the human study promotes not only the growth of interdisciplinary research, but also the formation of general psychological science, which would be better defined as a human science that was foreseen by B.G. Ananjev and whicn he insisted on on in his works (Ananjev, 1977). 
In domestic psychology, the development principle in the human mentality study is considered as the fundamental one (L.I. Antsyferova, A.V. Brushlinsky, L.S. Vygotsky, D.N. Zavalishina, A.V. Zaporozhez, V.P. Zinchenko, A.N. Leontiev, M.I. Lisina, B.F. Lomov, J.A. Ponomarev, V.B. Shvyrkov, Y.I. Aleksandrov and others) (see, for example, Aleksandrov, 2004; Ancyferova, Zavalishina, and Ry 'balko, 1988; Brushlinsky, 2003; Lomov, 1984; Sergienko, 1992; Shvirkov, 1988; Zaporozhecz, 2000). However, only a few are busy with the early ontogenesis development of human mentality. While the revolutionary changes, which are extremely important for the whole psychological science, are connected with the development psychology,this revolution is hardly reflected by the scientific community of our country, but is intensively discussed in the world psychology.

As long as several decades ago, many regulations on human knowledge of reality seemed to be settled and stable in psychology. Timid attempts to deviate from the traditional scheme were apprehended sharply and even oversensitively. How to describe the process of gaining knowledge of the world? At first, a person receives some sensations, while interacting with the world; then these sensations are transformed into perception of object or event, thus, we receive a perceptible image, which can become a representation and finally a conception, i.e. valuable knowledge of separate aspects of the world. The similar scheme of cognitive process broke off and separated the processes of sensation and perception, and the processes of thinking; moreover, it made the processes of the object choice, their subjective transformation, and description absolutely inexplicable.

In the cycle of works on studying the anticipation development in early human ontogenesis, stated in the author's works (Sergienko, 1992), it has been shown that anticipation is not only the attribute of the human activity, it is more universal, immanent characteristic of the human mind organization and evolution of forms of mind organization. Anticipation phenomena are considered not only as the spatio-temporal effects of anticipatory actions, but also as effects of selectivity. We may assume, that selectivity is a result of prototypical mechanism, while the space-time surpass of events modally reflects the specific mechanism of coding and mental storage. It is shown, that continuity is the basic characteristic of the human mind organization that defines the anticipation effects both in micro-and in macro-genesis. The given results are in line with the rep- resentations of close inseparable link with perceptive and thought processes, which are not realized consistently, but represented in the unified process of the cognitive analysis.

Modern cognitive psychology, starting with the works of J. Bruner (Bruner, 1977), R. Gregory (Gregory, 1970), W. Naisser (Naisser, 1981) and others, proceeds from the hypothesis that perception process is a process of acceptance of the intellectual decision, beyond which the perception does not exist. This decision is not realized and therefore, the subject of perception takes it as direct datum. Besides, this decision is possible only on the grounds of considering the perceived object among one or other class of subjects, one or other category, starting with the categories of objects ("table", "chair"), motion and ending with the categories of causality. Some of these categories (perceptive hypotheses) are formed on the basis of natural organizing principles (substantiality and continuity); the others are formed during the experiment. That is why, the perception is inseparable from thinking and has not only individual character, but generic, generalized, and universal as well. Hence, the lowest and the highest levels of mind organization are not diametrically opposed, but continuously interact (Lectorsky, 2001). At the heart of this continuity are the principles of anticipation, unity of perception, action, and representation.

These representations indicated the first thesis of revolutionary changes. The first thesis of revolutionary changes states that infant is not a sensory-motor individual, devoid of the ordered mental structures, and deep in chaos of sensations, as it was believed earlier. Infant is a representative individual who is richly talented in structuring and regulating the world.

The infants' ability to anticipate is a weighty argument confirming the drawn conclusion. A source of non-sensory conceptual activity of an infant is the representation of spatial characteristics of objects and events. Conceptually, the perceptive analysis of spatial structure may result in the mental descriptions of figurative schemes' type, which become precursory conceptions, such as "living", "agent", and "receptacle". Figurative schemes are the representation of perceptive structures of events, such as spatial attitudes and spatial motion, which characterize the event as a receptacle. Figurative schemes formation uses the active abstraction of the key information on the events that are coded in nonperceptive form, representing the value. These values are simple conceptions: "Top - bottom", "the part - the whole", "connection". The knowledge, based on such 
values, is unconscious and its content is filled up in the process of cognitive development of the child (Baillargeon, and Su-hua Wang, 2002; Meltzoff, and Moore, 1998; Sergienko, 1996; Spelke, et al., 1992).

In spatio-temporal effects of anticipation we find the proof of infants' ability to figurative schemes formation. Infants are able to anticipate the disappearance of an object. The presence of various strategy of searching movements of eyes is the reliable evidence that at the heart of this ability lays the spatial characteristics' representation. In our work, we clearly demonstrate that even two-month-old children show the discrete and continuous strategy in problems of object disappearance behind the screens of different size. The choice of adequate strategy of executive action points out the existence of internal representations, making a variation of executive behaviour possible (Sergienko, 1992).

The detailed analysis of infants' dynamics of executive actions (in the form of oculomotor strategy) gives rise to the idea that, most likely, there is at least a crude representation of the space, based on the ability to integrate space-time relations. The presence of congenital or early nascent ability to space representation does not mean that it is strictly programmed and invariable. It is rather a directional availability for integration, more exact setting is made by the problem itself. Representation of the space integrity is an important constituent of the physical world understanding, according to the use of continuity law (Sergienko, 1992; Spelke, et al., 1992).

Such an early "understanding" of some regulations of the physical world existence is proved to be true by facts about human neonate's imitation of facial (Field, Woodson, Greenberg, and Cohen, 1982) and manual gestures (Meltzoff, and Moore, 1977; 1998) of adults. Multiple confirmed experiments with infants' imitation make us agree, that long before the age of eigh months, estimated by Piaget as the first stage of sensory-motor integration, the infants demonstrate their ability to integrative actions, which assume a representation.

The inter-modal interaction is a certain mechanism of active representation formation. Our research on the functioning anticipatory schemes in the early period of infancy and data about the development of inter-modal interactions in conditions of early visual deprivation show, that there is a primary integration of perception and action, assuming the representation feature (Sergienko, 2004).
Data of numerous researches, including the researches by the author, count clearly in favour of the hypothesis of the infant's ability to representation (Baron-Cohen, 2000; Sergienko, 1996; Spelke, et al., 1992; Thelen, and Bates, 2003). Infants of the earliest period of development have an active representation of some aspects of the physical world existence. Thus, their ability to represent and to "interpret" the physical world develops at an early age, surpassing the ability to act actively in this world. Three or four-months' old babies are not capable of talking about objects, can not locomote around it and actively manipulate with it. Besides, they see the objects at low resolving capacity. At the same time, infants of this age can represent the objects that are dropping out of sight, interpret their latent movements, and "know" about their existence space. Infants represent the objects and their movement causality according to such characteristics of material bodies' behaviour, as continuity and substantiality (Sergienko, 1996).

The data, received by us and other researchers, refute Piaget's thesis that physical knowledge depends on interiority of sensory-motor structures and increases gradually in the process of formation of perception and action coordination. Besides, the results of conducted experiments negate the statements of various empirical theories supporters, asserting that solely actions in physical world can be the source of knowledge about it. Representations arise owing to this world objects active manipulation or locomotion around them; otherwise, representations are impossible till the mastering of language and gestures.

Our study of infants with a congenital cataract and congenially blind infants can serve as one of the arguments that action does not mediate the development of physical world knowledge so straight. These infants' actions with objects do not develop till the formation of the objects' constancy representations and they have essential developmental lag from sighted infants because of sight absence, which serves as the integrator in the interaction. Essential delays are also observed in locomotion development, which are also controlled and induced by the mental representation of environment (Fraiberg, 1977; Sergienko, 2002).

However, it does not imply an invariability of base representations. The role of perception and action as inseparable parts of any interaction, being improved, develops the representation, which has a congenital basis. This basis can be designated as a core or a kernel of knowledge or as an "anticipatory scheme". The constituent of this "anticipatory scheme" - in- 
troduction (representation) of the external world, which directs the perception and organizes the action, and that, in its turn, develops, changes, and supplements the original, base conception. The adduced proofs and facts count in favour of basics and very early basis of life conception, which the adult operates with, and deny the thesis about an invariability of conceptions.

Similar representations have something in common with I. Kant's idea of thinking spontaneity. The basis of thinking spontaneity is the ability for imagination (at the heart of which is the representation, if we use modern language). Owing to imagination, intellect creates its own conceptions, in addition to the consciousness control. Imagination workmanship is conditioned by finished structures (categories) and by empirical material. Categories have schemes. The schemes are the product of imagination. A priori knowledge, by Kant, differs from Plato's congenital ideas. Only forms are a priori (or the organization principles, in modern interpretation), as to the content, it entirely depends on experience. There are two a priori pre-experimental forms: space and time. Synthesizing activity of knowledge already begins at the level of feeling (compare it to the hypothesis of categoriality perception by J. Bruner and R. Gregory). Here a threefold synthesis becomes perceptible: grasping the representations, reduction of the varied contents of contemplation to the common image, further reproduction of representations in memory and, at the end, apperception - recognition, identification of representations with the phenomenon. This threefold synthesis is carried out on the basis of imagination. Categories penetrate into feelings, making them meaning-bearing. Categories are a priori, not congenital. They are created on their own during the clear mind epigenesis. J. Goethe emphasized, that Kant the first one to introduce the imagination as a necessary constituent part of the perception.

The cited philosophical views of Kant, in spite of their argumentativeness, cause direct analogies with modern representations of necessity of inclusion into perception the anticipatory schemes, assuming selectivity and ordering of interaction, and with modern representations of self-development, including thinking, when the internal mechanisms of development are as potentials (forms), which are realized (content) through the environmental experience, according to the laws of the environment organization. The epigenesis principle resolves the contradiction in dichotomy of genes-environment, biological-social, congenital - acquired.
The second thesis of revolutionary conceptual changes is connected with the first one. According to the classical theories of mental development, conceptions' formation is caused by the actions of infants. The modern developmental psychology has shown, that long before the infant is capable to carry out manipulations with objects and to move actively, he is more cognitively competent, than it was imagined before. Perception and action are integral parts of the uniform system of interactions controlled by the general laws.

On the basis of other authors' research (Bertenthal, 1996; Sergienko, 2004) and at first hand, in the field of early ontogenesis, the author offers a hypothesis of the opportunity to mark out two functional subsystems in the uniform system of perception and action - perceptual control of action and identification. Differences in the functioning organization of these subsystems are in the positions of interaction with the surrounding world (allocentric - egocentric), type of coding and storage of the information (amodal coding - modally specific), degree of realization (the higher degree is typical for identification system), and peculiarities of anticipation effects (space-time anticipation - selective expectation).

Both subsystems develop from the moment of birth; however, the subsystem perceptual control achieves more mature level of organization before identification subsystem. In spite of dissociation features between two subsystems, their functioning is controlled by representations organized hierarchically and become more active according to the tasks. Coordination of perception and action takes place through the abstract structures of representation, which can be amodal and modally-specific as well. What format of knowledge storage will be used depends on the kind of problem the subject faces. It seems, that both types of representative storage develop ever since the birth, but amodal coding provides the base levels of information processing to a greater extent, than the modal-specific coding, as it gives the most general representation of space - time characteristics of the objects, events and ways of actions. Detailed elaboration of a scene assumes the modal-specific coding and higher organized levels of the actions organization. Thus, we believe in the existence of level organization of representations - perceptions - actions.

Another major aspect of revolutionary changes in developmental psychology, touching cognitive development as well, is the problem of human formation as a subject. 
In domestic psychology, with hypersocialization as a dominant, infant's mental development is responsibility of adult as a representative of society, without which any development of the supreme mental functions is impossible. The author carried out a number of works in this direction (Sergienko, 1992; 1996; 2002). In the view of the similar hypersocialized approach, the infant remains an influence object, not the subject. Our point of view is that the infant since the beginning of his existence (perinatal life) is provided with his own individuality, which is formed of the type originality of its structures and functions, which, certainly, include general, specific, universal components, especially unique ones. This individual component of the infant's (at first, a fetus') behaviour is determined not only by the uniqueness of his genetic roots, but also by the uniqueness of his development history, which, along with typical nature, brings its peculiarities into the infant's behaviour, abilities, and his mental world formation.

Therefore, we consider it necessary to take proper account of human individuality at all stages of his development. Human individuality is closely connected with the subject's category. The given category, to which such scientists as S.L. Rubinstein, KA. Abulkhanova, B.G. Ananjev, D.N. Uznadze and many others made a huge contribution (Sergienko, 2002), is fully developed by A.V. Brushlinsky within the framework of the subject-activity approach (Brushlinsky, 2003).

Development of a person as a subject is continuous in human ontogenesis, opening the levels of his formation, which have specific criteria (the third thesis). Thus, all levels are interconnected and correlated that assumes a historical connection of the level criteria of subjectivism (Sergienko, 2002). It was originally offered to single out two levels: protosubjectivism (primary subjectivism (separating oneself as a subject of interaction from the external world and the world of other people about two-monthsold or younger) and secondary subjectivism (infant's ability to share the common mental state with other people - a triangle of relations - I-object - the other person - about nine-months'old).

During the last years, researchers singled out two more levels connected with the formation of the model of mind, which reflect the opportunities of human behaviour as a subject of activity (Sergienko, 2005). Thereupon, the experimental and theoretical analysis has separated the level of an agent (3-4 years' old) and the level of a naive subject (5-6 years' old). At the level of an agent, the infant can start to separate his own model of mind from the model of mind of all others. Though the comparison of these models is still complicated, it is possible only in the primitive situations that allow to predict the consequences of own and others' actions, whereas the manipulations with the others' model of mind are still inaccessible. For example, children of 3-4 years can already understand that if they know that the box of sweets is used for keeping threads, the other may not know it and make a mistake, trying to take a candy from this box. As for children up to 3-4 years, they identify their knowledge, emotions, and intentions with the knowledge, emotions and intentions of others. At the level of a naive subject, there is an ability of understanding and comparison of models of mind (I the other person). Such comparison leads to the attempts to manipulate the model of others with the purpose of changing the representations of event or causality: i.e. the ability to deception forms. First, deception appears as a cognitive phenomenon of mental development, and only later there is a moral aspect of deception as a reflection of social norms and rules of interaction of people.

In foreign researches of mind understanding (Theory of Mind) there are disagreements in determining the age, at which the human being starts to understand (Baron-Cohen, 2000; Meltzoff, and Moore, 1998; Perner, 1991). This ability has proved to be vulnerable for testing, and depending on the task, conditions of its presentation, different ages are named (from 3 till 6 years). But the majority of authors name the age of fouryears as the period of formation of the mind model, the time when the children are capable to understand the problem of incorrect opinions. Many authors consider the very problem of incorrect opinion as a key for mind model. Level approach to the analysis of formation of mind model removes the mentioned disagreements, and the use of various tasks in one research helps to avoid mistakes in interpretation.

The general conclusion of works in the Theory of Mind direction consists in the criticism of J. Piaget's conceptions about representative intelligence formation (Perner, 1991). We should remind, that Piaget considered that infants could understand other people only at the stage of specific operations when they overcome egocentrism of thinking, which does not let to present any other point of view, other perspective . Children at the age of four are capable to understand the mental conditions of others; hence, one cannot speak about egocentrism of thinking. 
In J. Perner's recent work with colleagues (Meltzoff, and Moore, 1998; Perner, 1991), the different understanding of criticism of J. Piaget's theory was offered. For describing the intellectual development Piaget used verbal descriptions, which showed how children progressed to revelation of the properties of logic universe in a stream of independent egocentric perspectives, coordinating these perspectives into an objective picture. For example, the relations of objects of "a tree behind the stone" and "a tree in front of the stone" types as relations of A-B and $\mathrm{B}-\mathrm{A}$ can not be integrated without understanding that these are the different points of view on the same scene: relations of your and my perspectives. Hence, the way of mutual relations understanding is in interpretation of the scene components as belonging to different perspectives . Little by little, infants come to this integration. First, they reveal different perspectives, and then they gain ability to the different perspectives' confrontation, and only after that the multiperspective vision. The ability to confrontation of perspectives appears at the age of four, and it is connected with the problems of incorrect opinion. So, if Bill has left a chocolate in the box A and his mother put it to the box $\mathrm{B}$, Bill, having returned will look for it in box A. Bill's incorrect opinion would not be in agreement with the reality (chocolate is in box B). Beat is wrong thinking that chocolate is in box A, but the chocolate had been there and this is a true opinion. Whereas the problem of A being behind $\mathrm{B}$, and $\mathrm{B}$ being in front of $\mathrm{A}$ depends only on the position of the observer, that demands multiperspective representation (same as in the problem of Piaget called "Three mountains") and starts to form at the age of seven-eight (just as by Piaget).

There are two conclusions following these comparisons. The first conclusion is that our opinion on necessity of the level analysis of mind model formation and of more versatile analysis of the problems in these researches is proved. The second conclusion is that in Piaget's theory infant's cognitive development apparently dissociates with development of his understanding and requires the other level of mental organization. Then, Piaget's criticism is reduced to the criticism of description of other cognitive development aspects, based on metacognitive structures' formation at preoperational and specific mentality levels.

The fourth thesis deals with the representations dominating not only in the majority of people, but in experts as well. It states that early development of an infant is under a much more intensified genetic con- trol, than at older age, and especially in the adult period. Revolutionary changes of these representations are connected with psychogenetic data that have demonstrated the extension of genetic effect on variability of mental development after a number of years and the maximum effect at middle age. Psychogenetic constrains to reconsider the representations of critical periods and their determination, significantly contribute to genetic factors in the development of speech and individuality i.e. to reconsider the understanding of key regulations of the determinants of mental and cognitive developments (Reznick, Corley, and Robinson, 1997; Sergienko, 2002; Spelke, et al., 1992). Does it mean that it is necessary to abandon the representations of importance of surroundings and social factors in the infant mental development? Certainly, it does not. Genetic concept without environmental one, as well as environmental concept without genetic one are absolutely empty. These two forces make a persistent continuum of interactions, only the "force" of their applications to the different moments of human life and to different abilities is changed (Sergienko, 2002).

In conclusion, the author should emphasize that she considers the presented analysis of revolutionary changes in cognitive and developmental psychology as the current situation. Many questions brought up here require development and more detailed research. However, one thing remains constant - the belief that the development problems' solving is in the genetic approach and psychology can reveal the essence of mental phenomena only by the analysis of development dynamics.

\section{References}

Aleksandrov, Y.I. (2004). Nauchenie i pamyat': sistemnaya perspektiva [Learning and memory: system prospects]. In Vtory 'e simonovskie chteniya [Second Simonov readings]. Moskva: Russian Academy of Science.

Ananjev, B.G. (1977). O problemakh sovremennogo chelovekoznaniya [Problems of modern study of human nature]. Moskva: Nauka.

Ancyferova, L.I., Zavalishina, D.N., and Ry`balko, Y.F. (1988). Kategoriya razvitiya v psikhologii [Category of development in psychology]. In L.I. Ancyferova (ed.). Kategorii materialisticheskoj dialektiki $v$ psikhologii [Categories of materialistic dialectics in psychology]. Moskva: Nauka. P. 9-36.

Baillargeon, R., and Su-hua Wang. (2002). Event categorization in infancy. Trends in Cognitive Science, 6, 2. P. 75-105. 
Baron-Cohen, S. (2000). Theory of mind in autism: A fifteen year review. In S. Baron-Cohen, H. Tager-Flusberg, and D. J. Cohen (Eds.). Understanding other minds: Perspectives from developmental cognitive neuroscience. New York: Oxford University Press. P. 3-20.

Bertenthal, B.I. (1996). Origins and early development of perception, action and representation. Annu. Rev. Psychol., 47. P. 431-459.

Bruner, J. (1977). Psikhologiya poznaniya [Knowledge psychology]. Moskva: Progress.

Brushlinsky, A.V. (2003). Psikhologiya sub 'ekta [Subject psychology]. Moskva: Aleteya.

Field, T.M., Woodson, R., Greenberg, R., and Cohen, D. (1982). Discrimination and imitation of facial expressions by neonates. Science, 218. P. 179-181.

Fraiberg, S. (1977). Insight from the blind. Comparative studies of blind and sighted infants. N.Y.: Basic Books, Inc.

Gregory, R.L. (1970). Glaz i mozg. Psikhologiya zritel nogo vospriyatiya [Eye and brain. Psychology of visual perception]. Moskva: Progress.

Lectorsky, V.A. (2001). Epistemologiya klassicheskaya i neklassicheskaya [Classical and nonclassical epistemology]. Moskva: URSS.

Lomov, B.F. (1984). Metodologicheskie i teoreticheskie problemy ' psihologii [Methodological and theoretical problems of psychology]. Moskva: Nauka.

Meltzoff, A., and Moore, M.K. (1977). Imitation of facial and manual gestures by human neonates. Science, 218. P. 179-181.

Meltzoff, A., and Moore, M.K. (1998). Object representation, identity and paradox of early permanence: steps to the new framework. Infant behaviour and development, 21, 2. P. 201-235.

Naisser, U. (1981). Poznanie i real'nost'. Smysl i principy kognitivnoj psihologii [Knowledge and reality. The Purport and principles of cognitive psychology]. Moskva.

Perner, J. (1991). Understanding the representational mind. Cambridge, Massachusetts: MIT Press.

Reznick, Y.S., Corley, R., and Robinson, J. (1997). A longitudinal twin study of intelligence in the second year. Monographs of society for research in child development 62, 1, 249. P. 166.

Sergienko, E.A. (1992). Anticipaciya v rannem ontogeneze cheloveka [Anticipation in human early ontogenesis]. Moskva: Nauka.

Sergienko, E.A. (1996). Istoki poznaniya: ontogeneticheskij aspekt [Origins of knowledge: ontogenetic aspect]. Psihologicheskij zhurnal, 17, 4. P. 43-54.

Sergienko, E.A. (2002). Rannie etapy` razvitiya sub “ekta [Early stages of the subject's development]. In A.V. Brushlinskij (ed.). Psihologiya individual'nogo i gruppovogo sub'ekta [Psychology of individual and group subject]. Part 5. Moskva. P. 270-310.
Sergienko, E.A. (2004). Vospriyatie i dejstvie: vzglyad na problemu s pozicii ontogeneticheskikh issledovanij [Perception and action: View on the problem from positions of ontogenetic researches]. J. Psihologiya, I, 2. P. 16-38.

Sergienko, E.A. (2005). Razvitie modeli psihicheskogo kak mental’ny ’j mehanizm stanovleniya sub " ekta [Development of mind model as a mental model of subjectivism formation]. In V.V. Znakov, Z.I. Ryabikina (eds.). Sub ' ekt, lichnost', psihologiya chelovecheskogo by tiya [The subject, the person, psychology of human life]. Moskva: Izdatel'stvo "Institut psihologii RAN". P. 243-270.

Shvirkov, V.B. (1988). Sistemno-evolyucionny`j podkhod k izucheniyu mozga, psihiki i soznaniya [System-evolutionary approach to the study of brain, mentality, and consciousness]. Psihologicheskij zhurnal, 9, 1. P. 132-148.

Spelke, E., et al. (1992). Origins of knowledge. Psychological Review, 99, 4. P.605633.

Thelen, E., and Bates, E. (2003). Connectionism and dynamic systems: are they really different? Developmental Science, 6, 4. P. 378-392.

Thelen, E., and Smith, L. (1994). Dynamic systems approach to the development of cognition and action. Cambridge, MA: MIT Press.

Thelen, E., and Smith, L. (1998). Dynamic systems theories. In Theoretical models of human development. Handbook of child psychology, V. 1. N.Y.: Wiley.

Zaporozhecz, A.V. (2000). Psihologiya dejstviya [Psychology of action]. MoskvaVoronezh: Izdatel'stvo Moskovskogo psihologo-social’nogo instituta. 